\title{
Influence of the Steel Fiber Content on the Flexural Fatigue Behavior of Recycled Aggregate Concrete
}

\author{
Yan Tan (iD, Chenxu Zhou (D), and Jinzhi Zhou (iD \\ School of Civil Engineering, Architecture and Environment, Hubei University of Technology, Wuhan 430068, China \\ Correspondence should be addressed to Jinzhi Zhou; zhoujinzhi@hbut.edu.cn
}

Received 9 September 2020; Revised 26 October 2020; Accepted 30 October 2020; Published 12 November 2020

Academic Editor: Mehmet Serkan Kirgiz

Copyright (c) 2020 Yan Tan et al. This is an open access article distributed under the Creative Commons Attribution License, which permits unrestricted use, distribution, and reproduction in any medium, provided the original work is properly cited.

\begin{abstract}
Steel fiber recycled aggregate concrete (SFRAC) is mainly used in roads, bridges, and railways that are subjected to bear wheel load. This paper presents a comparative experimental study on the flexural fatigue behavior of the SFRAC, the natural aggregate concrete (NAC), and the recycled aggregate concrete (RAC). The results show that, with the use of $1.0 \%$ volume fraction steel fiber, the flexural strength of SFRAC exceeds the flexural strength of NAC (around 0.3\%), and the fatigue lives of RAC have been found to be lower by $19.9 \%$ and $53.4 \%$ compared to SFRAC at stress levels $S=0.9$ and $S=0.7$. The fatigue strain of SFRAC follows the three-stage law, and the fatigue strain of SFRAC develops more slowly than that of RAC at the same stress level. Two-parameter Weibull distribution is fitted to the test data to generate fatigue models at different survival probabilities, and fatigue life can be accurately predicted using the developed model. Therefore, it is feasible to replace the natural concrete with the recycled aggregate concrete with appropriate steel fiber content in some aspects, which is of great significance to green development.
\end{abstract}

\section{Introduction}

In the past few decades, consumption of natural aggregates rises as a result of the rising demand for concrete. As the old concrete buildings are abandoned, more waste concrete in the city has an increasingly serious impact on the ecological environment. The recycling of waste concrete has aroused scholars' wide interest and positive participation [1]. Recycled aggregate concrete (RAC) is a kind of material using waste concrete made into recycled aggregates to replace natural aggregates partly or totally by the processes of washing, crushing, screening, and being mixed proportionally. Yazdanbakhsh et al. [2] concluded that the reuse of concrete waste has a $16 \%$ and $17 \%$ lower impact on acidification and smog compared to natural aggregates. The use of recycled concrete can not only improve the direct adverse impact of waste concrete on the environment but also indirectly benefit the protection of the ecological environment by reducing the extraction of natural aggregates. The economic and environmental benefits are significant [3].

RAC is mainly used in roads, bridges, and railways. Fatigue strength is the main parameter of RAC, which stimulates great excitement among scholars. Numerous researchers have recently been undertaken to explore the fatigue behavior of recycled concrete. Arora and Singh [4] concluded that, at the same stress level, the theoretical fatigue life of recycled concrete aggregates is lower than that of natural aggregates. Xiao [5] proposed an inverted-S nonlinear fatigue damage cumulative model using the fatigue test results of recycled concrete based on the three-phase law of fatigue damage evolution and investigated the damage evolution and fatigue life of recycled concrete. Thomas [6] studied the fatigue limit of concrete with partial and total coarse aggregate replacement in response to repeated compressive loads. The results show that, for the same water/ cement ratio, the recycled aggregate concrete presents a loss of stiffness higher than the control concrete. Furthermore, the use of recycled aggregates in concrete implies a reduction in fatigue life. Xiao [7] investigated the fatigue behavior of recycled aggregate concrete with $100 \%$ recycled coarse aggregate replacement percentage under uniaxial compression and cyclic bend loading, and it is found that there exist no obvious differences in compressive fatigue behavior between $\mathrm{RAC}$ and natural aggregate concrete (NAC), and the fatigue 
life of RAC is lower than that of NAC for the same stress level under cyclic bend loading. However, it is generally believed that the physical and mechanical properties of recycled concrete will decrease, and the fatigue life will be shortened [2-7].

In the past several decades, numerous studies have explored the fatigue behavior of RAC wherein various types of materials were incorporated including rubber $[8,9]$, asphalt [9-14], and steel fiber [15], which generally suggested that the incorporation of the above fibers with suitable materials improved the fatigue performance of concrete considering different conditions, e.g., stress ratio and specified material properties.

Consequently, researches have shown that the incorporation of the steel fiber into plain concrete can improve fatigue behavior. Fang [16] investigated the fatigue properties of RPC (reactive powder concrete) with different steel fiber ratios with the uniaxial compressive fatigue test. The results show that the fatigue life and strength increase with the increase in steel fiber ratio. Mei [17] obtained the fatigue lives of common concrete and steel fiber-reinforced polymer concrete at the age of $90 \mathrm{~d}$ and test stress levels of $0.4,0.5$, and 0.6 , respectively, by the three-point bending fatigue test. The results show the fatigue lives of common concrete and steel fiber-reinforced polymer concrete under cyclic loading are consistent with two-parameter Weibull distribution; the fatigue life of steel fiber-reinforced polymer concrete is higher than that of common concrete under the same stress level. Feng [18] studied the fatigue behavior of concrete with a different steel fiber content and obtained the fatigue performance of steel fiber concrete is significantly higher than that of ordinary concrete, and its fatigue strength is about $20 \%$ higher than that of ordinary concrete. Goel and Singh [19] adopted the parameters of Weibull distribution to predict the fatigue of self-compacting concrete reinforced with steel fiber considering different failure probabilities and noted that the steel fiber enhanced the overall fatigue behavior of concrete. The aggregate shape can also influence the mechanical properties of the steel fiber concrete [20-22].

Although the steel fiber has improved the performance of concrete, it has also caused an irreversible impact on the ecological environment under the requirements of green and low carbon. The increasing concrete consumption, especially sand, stone, and other raw materials for the production of concrete, motivated researchers to explore the fatigue behavior of recycled concrete with steel fiber content. Yang and Wei [15] concluded that the steel fiber-reinforced recycled concrete residual fatigue strain equation and comparisons are made with other expressions, showing that the proposed model is the most consistent with the experimental results. However, the SFRAC research is little, especially the influence of the steel fiber content on the flexural fatigue behavior of recycled concrete is never investigated. Therefore, it is very necessary to find the appropriate amount of steel fiber to verify that recycled concrete with the steel fiber content has good fatigue properties. The recycled concrete with appropriate steel fiber content can replace natural aggregate concrete in some aspects, which is of great significance for green development and also provides a theoretical basis for the practical application of SFRAC.

This paper aims to investigate the flexural fatigue behavior of SFRAC considering two main influencing factors, i.e., stress ratios and steel fiber content. Firstly, 72 SFRAC beams with $150 \mathrm{~mm} \times 150 \mathrm{~mm} \times 550 \mathrm{~mm}$ were prepared, in which $20 \%$ of natural coarse aggregate was replaced by the recycled coarse aggregate to make the RAC and added the volume ratios with $0.5 \%, 1.0 \%, 1.5 \%$, and $2.0 \%$ steel fiber; then, a four-point bending test was performed on the concrete beams to obtain the maximum and minimum loads under different stress levels in the fatigue test; more importantly, flexural fatigue tests were carried out using three stress ratios (i.e., $0.9,0.7$, and 0.6 ), and corresponding fatigue life data of mixtures with all kinds of mix ratio were processed using the two-parameter Weibull distribution. The Weibull distribution parameter was obtained to predict the fatigue life data of all mixtures corresponding to various survival probabilities, and the fatigue equations were then developed. The $\varepsilon$ - $\mathrm{N}$ curves of different mixtures under different stress levels were also analysed. Lastly, the SFRAC with the best fatigue life was compared with previous researches using steel fiber natural aggregate concrete to verify the effectiveness of SFRAC in possible practical applications.

\section{Materials and Methods}

2.1. Raw Materials. The design strength grade of the concrete matrix was C30. Portland cement (P.O 42.5) was used as a binder material for all tested mixtures. An analysis was made of the physical, chemical, and mechanical characteristics of the cement used. The results obtained were considered adequate taking into account the GB175-2007 [23]. Figure 1 shows the natural coarse aggregate and recycled coarse aggregate used in this work. Recycled coarse aggregates are formed by crushing waste concrete pavement. The coarse aggregate was of uniformly continuous grading with a size of 5 to $31.5 \mathrm{~mm}$, as shown in Figure 2. The basic performance indicators of coarse aggregate are shown in Table 1. River sand and machined sand are used in this work. Natural river sand with a specific gravity of 2.66 and with a maximum size of $5 \mathrm{~mm}$ was used as fine aggregate, which belongs to medium sand in zone II. The apparent density is $2640 \mathrm{~kg} / \mathrm{m}^{3}$, and the bulk density is $1642 \mathrm{~kg} / \mathrm{m}^{3}$. The machined sand with a specific gravity of 3.1 and a maximum size of $5 \mathrm{~mm}$ was used as fine aggregates. Particle-size distribution of the aggregates used in this study is shown in Figure 2.

The steel fiber was a rectangular corrugated steel fiber of size $35 \times 2.0 \times 0.8 \mathrm{~mm}$, a tensile strength of $538 \mathrm{MPa}$, and a steel fiber density of $7850 \mathrm{~kg} / \mathrm{m}^{3}$ in Figure 3 . The class I fly ash was provided by a company in Hubei. The fineness is 325 mesh, the density was $2.4 \mathrm{~g} / \mathrm{cm}^{3}$, the moisture content is $0.5 \%$, and the loss on ignition is $3.6 \%$. The produced S95 grade mineral powder had a density of $2.9 \mathrm{~g} / \mathrm{cm}^{3}$ and a specific surface area of $435 \mathrm{~m}^{2} / \mathrm{kg}$. The admixture was the polycarboxylate superplasticizer. The water reduction rate is $24 \% \sim 26 \%$, and the gas content is $4.6 \%$. As there is 


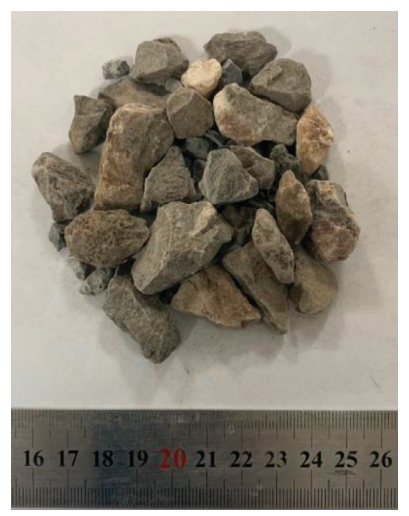

(a)

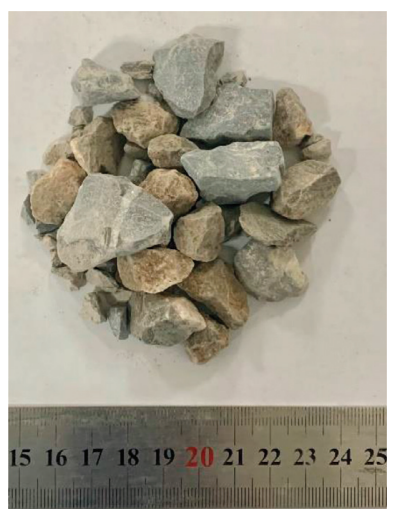

(b)

FIGURE 1: Coarse aggregate: (a) natural coarse aggregate; (b) recycled coarse aggregate.

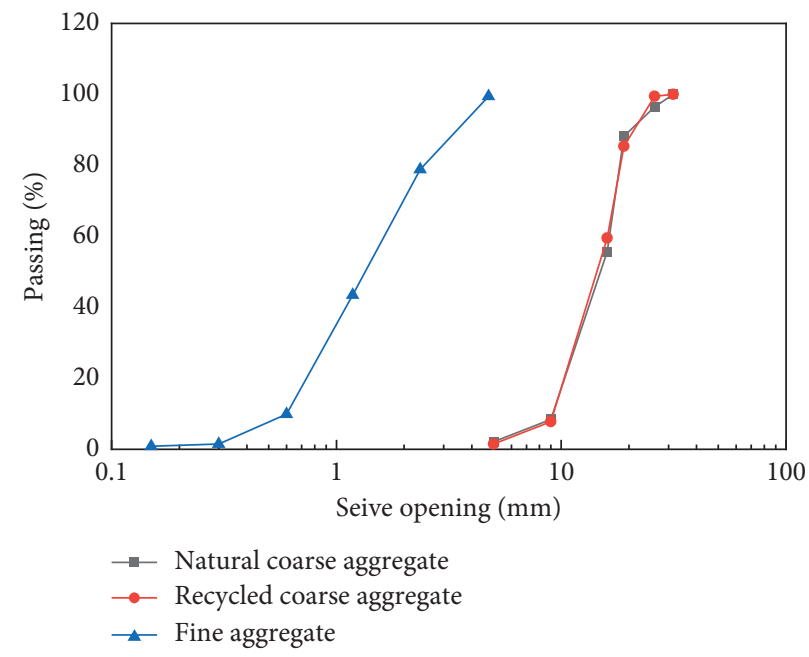

FIgURE 2: Particle-size distribution of the aggregates used in this study.

TABle 1: Basic properties of coarse aggregate, $\mathrm{kg} / \mathrm{m}^{3}$.

\begin{tabular}{lccccc}
\hline Coarse aggregate & Apparent density & Bulk density & Water absorption (\%) & Mud content (\%) & Crushing index (\%) \\
\hline Natural aggregate & 2648 & 1340 & 0.9 & 0.45 & 9.0 \\
Recycle aggregate & 2520 & 1250 & 9.5 & 0.69 & 14.9 \\
\hline
\end{tabular}

dispersant in cement concrete, it can comprehensively improve various properties of concrete.

2.2. Mixtures Design. The minimum value of the NAC compressive strength is $30 \mathrm{MPa}$, according to JGJ 55-2011 [24]. The natural coarse aggregate was replaced with recycled coarse aggregate, and the replacement rate was $20 \%$. Too high-steel fiber content will cause high cost and lose practical application value. Six groups of test mixtures with two different replacement ratios of recycled aggregates (i.e., 0 and 20\%) and four different dosages of steel fibers (i.e., 0, 0.5, 1.0 , and $1.5 \%$ of the volume of aggregate concrete) were prepared. SF0.5RAC, SF1.0RAC, SF1.5RAC, and SF2.0RAC are steel fiber recycled concrete with $0.5 \%, 1.0 \%, 1.5 \%$, and $2.0 \%$ steel fiber content. According to the GB/T 50081-2002 [25], a $150 \mathrm{~mm} \times 150 \mathrm{~mm} \times 550 \mathrm{~mm}$ beam was used for the four-point bending test in this test. The arithmetic average of three test pieces with the same mix ratio was used as the final result. The mixture design of concrete is summarized in Table 2.

2.3. Flexural Fatigue Test Design. A four-point bending test was conducted on an MTS servo-controlled actuator, as shown in Figure 4. And this result was used to fix the minimum and maximum loads to perform flexural fatigue tests on the remaining mixtures of the batch. The fatigue loads were applied in the form of sinusoidal loads with constant amplitude at a loading frequency of $10 \mathrm{~Hz}$ at different stress levels $(S)$ including $0.6,0.7$, and 0.9 , where $S$ stands for the ratio of maximum fatigue stress to average flexural strength. The stress ratio $(\mathrm{SR}), \mathrm{SR}=$ the maximum load $\left(F_{\max }\right)$ the minimum load $\left(F_{\min }\right)$, was kept constant as 


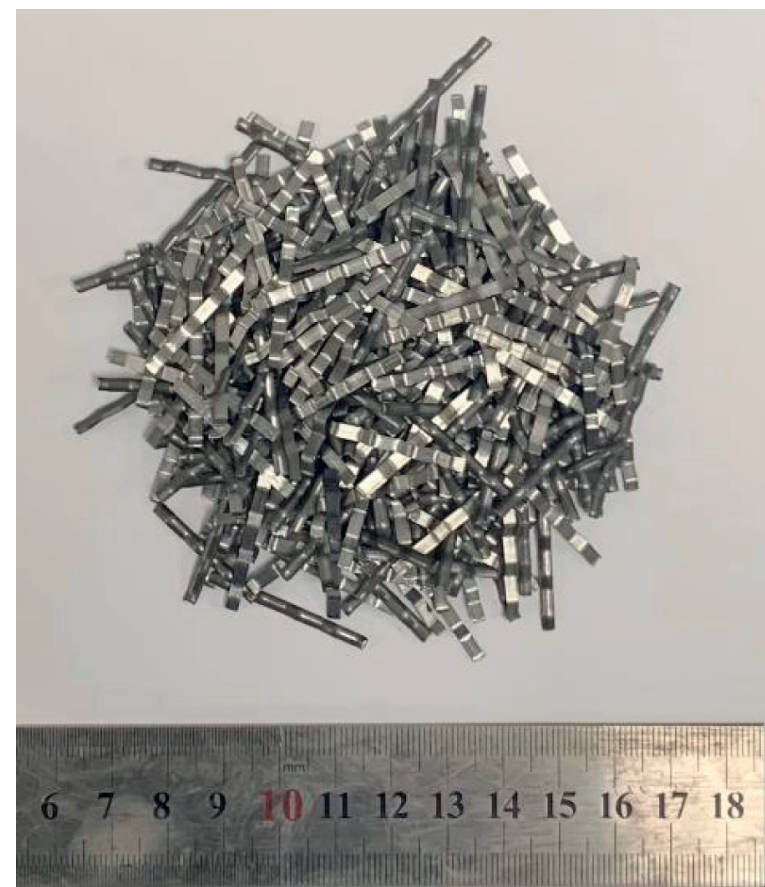

FIgUre 3: Steel fiber.

TABle 2: Mixtures design of concrete, $\mathrm{kg} / \mathrm{m}^{3}$.

\begin{tabular}{|c|c|c|c|c|c|c|c|}
\hline Mixture & & NAC & RAC & SF0.5RAC & SF1.0RAC & SF1.5RAC & SF2.0RAC \\
\hline Cement & & 210 & 210 & 210 & 210 & 210 & 210 \\
\hline \multirow{2}{*}{ Coarse aggregate } & Natural & 1030 & 824 & 824 & 824 & 824 & .824 \\
\hline & Recycle & 0 & 206 & 206 & 206 & 206 & 206 \\
\hline \multirow{2}{*}{ Fine aggregate } & Mechanism sand & 380 & 380 & 380 & 380 & 380 & 380 \\
\hline & River sand & 455 & 455 & 455 & 455 & 455 & 455 \\
\hline \multirow{2}{*}{ Mineral admixture } & Fly ash & 60 & 60 & 60 & 60 & 60 & 60 \\
\hline & Mineral powder & 100 & 100 & 100 & 100 & 100 & 100 \\
\hline Admixture & & 12.58 & 15.91 & 15.91 & 15.91 & 15.91 & 15.91 \\
\hline Water & & 160 & 160 & 160 & 160 & 160 & 160 \\
\hline Steel fiber & & 0 & 0 & 39.3 & 78.5 & 117.8 & 157 \\
\hline
\end{tabular}

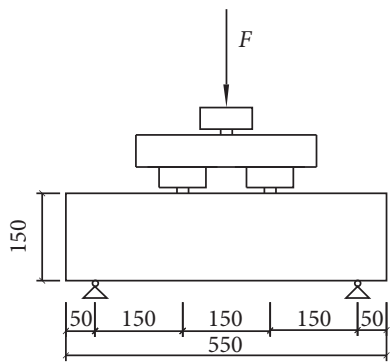

(a)

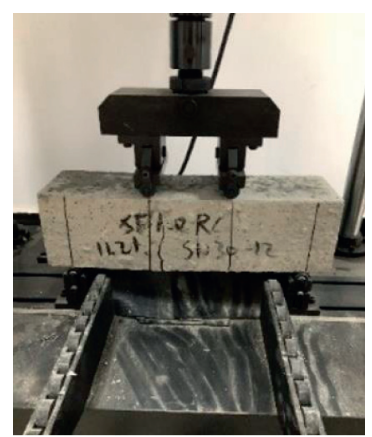

(b)

Figure 4: Four-point bending test: (a) scheme; (b) test picture.

0.10 for all fatigue tests conducted in this study. The $F_{\max }$ and the $F_{\min }$ of different $S$ in the fatigue test were obtained, as shown in Table 3. An example of a cyclic loading applied on a beam from the NAC mixture is shown in Figure 5. In Figure 6 , the fatigue test was terminated either when the beam cracks or when the specimen exceeds 2,000,000 
TABLE 3: Loading parameters $\left(F_{\max }\right.$ and $\left.F_{\min }\right)$.

\begin{tabular}{|c|c|c|c|c|}
\hline Mixture & Bending load $(\mathrm{kN})$ & $S$ & $F_{\max }(\mathrm{kN})$ & $F_{\min }(\mathrm{kN})$ \\
\hline \multirow{3}{*}{ NAC } & \multirow{3}{*}{44.25} & 0.6 & 26.55 & 2.66 \\
\hline & & 0.7 & 30.98 & 3.10 \\
\hline & & 0.9 & 39.83 & 3.98 \\
\hline \multirow{3}{*}{ RAC } & \multirow{3}{*}{39.18} & 0.6 & 23.51 & 2.35 \\
\hline & & 0.7 & 27.43 & 2.74 \\
\hline & & 0.9 & 35.26 & 3.53 \\
\hline \multirow{3}{*}{ SF0.5RAC } & \multirow{3}{*}{42.68} & 0.6 & 25.61 & 2.56 \\
\hline & & 0.7 & 29.88 & 2.99 \\
\hline & & 0.9 & 38.41 & 3.84 \\
\hline \multirow{3}{*}{ SF1.0RAC } & \multirow{3}{*}{44.36} & 0.6 & 26.62 & 2.66 \\
\hline & & 0.7 & 31.05 & 3.11 \\
\hline & & 0.9 & 39.92 & 3.99 \\
\hline \multirow{3}{*}{ SF1.5RAC } & \multirow{3}{*}{42.21} & 0.6 & 25.33 & 2.53 \\
\hline & & 0.7 & 29.55 & 2.96 \\
\hline & & 0.9 & 37.99 & 3.80 \\
\hline \multirow{3}{*}{ SF2.0RAC } & \multirow{3}{*}{39.62} & 0.6 & 23.77 & 2.38 \\
\hline & & 0.7 & 27.73 & 2.77 \\
\hline & & 0.9 & 35.66 & 3.57 \\
\hline
\end{tabular}

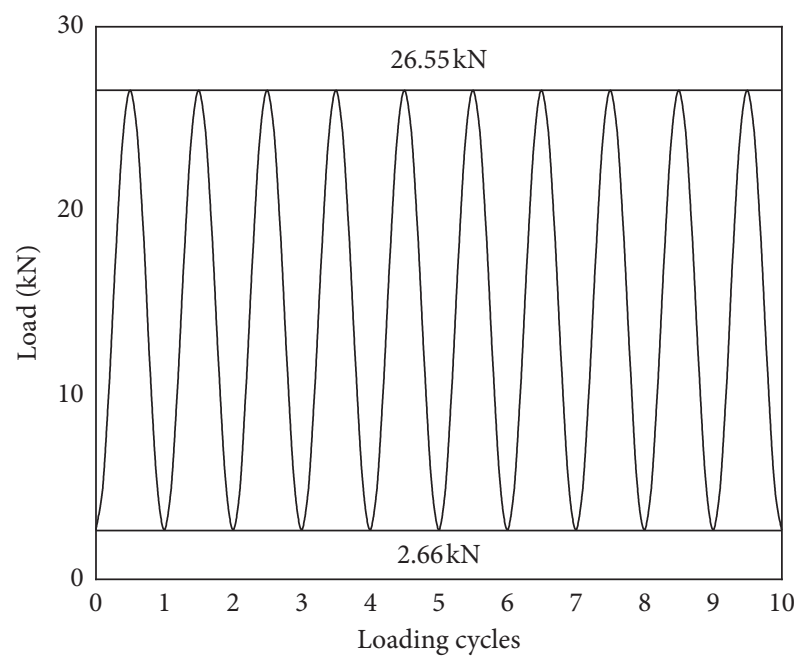

FIGURE 5: Example of loading cycles.

loading cycles without failure.

\section{Test Results and Analyses}

3.1. Flexural Strength Analysis. Figure 7 shows the $28^{\circ} \mathrm{d}$ flexural strength of all mixtures and the curve of the relative to NAC flexural strength of mixture. When the steel fiber volume fraction is less than $1.0 \%$, the flexural strength of concrete increases with the increase in steel fiber volume fraction. With the addition of $1.0 \%$ volume of steel fiber, the flexural strength of SF1.0RAC exceeds the flexural strength of NAC (around $0.3 \%$ ). When the steel fiber volume fraction is greater than $1 \%$, the flexural strength of concrete decreases with the increase in steel fiber volume fraction. The addition of steel fiber can improve the flexural strength of RAC and make up for the adverse effect of recycled aggregate on the flexural strength of concrete. When the steel fiber content is $1.0 \%$, the flexural performance of recycled concrete is best improved, and the flexural strength of steel fiber recycled concrete reaches the flexural strength of NAC.

3.2. Flexural Fatigue Results. The flexural fatigue testing results for mixtures at different $S$ are shown in Table 4. The fatigue lives of RAC have been found to be lower by $19.9 \%$ and $53.4 \%$ compared to SF1.0RAC at stress levels $S=0.9$ and $S=0.7$. The $S$ is typically plotted with the logarithm of the resulted $N$ from fatigue testing in a graph commonly known as the $\mathrm{S}-\mathrm{N}$ curve.

Figure 8 shows in the S-N curves in this study that, for all kinds of mixtures, increasing $S$ reduced their fatigue life, as expected. Under the effect of fatigue loads, the small defects gradually develop and expand eventually leading to mixtures failure. When the $S$ increases, initiated microcracks and higher crack propagation rate are induced by a higher $S$, and thereby, more cumulative cracks are presented inside the concrete, which finally speeds up the ultimate failure of the concrete. When the $S$ is constant, the fatigue life of RAC is lower than that of NAC, but with the addition of steel fibers, the fatigue life of recycled concrete is longer than that of RAC. RAC has more microcracks than NAC. With the addition of $0.5 \%, 1.0 \%, 1.5 \%$, and $2.0 \%$ volume of steel fiber, the fatigue life of recycled concrete increases first and then decreases, but it is still longer than the fatigue life of RAC. SF1.0RAC has the longest fatigue life, which is not only equivalent to that of NAC but also 1.85 times equivalent to that of RAC. The steel fibers are more evenly dispersed in the concrete at this time so that all parts of the concrete sample are uniformly stressed, and the fatigue life is longer. However, when the steel fiber content exceeds $1.0 \%$, the fatigue life of the mixture decreases. Too much steel fiber cannot be evenly distributed in the mixture, resulting in too much steel fiber in the inner part of the concrete and less concrete matrix. The steel fiber, aggregate, and mortar can bear the cyclic load capacity. It shows that a reasonable amount of steel fiber can effectively improve the fatigue life of recycled concrete and offset the defects of recycled aggregate.

3.3. Evolution of Fatigue Damage. As shown in Figure 9, the $\varepsilon$-N curves of mixtures basically comply with three main stages of fatigue strain development under different $S$ [15]: (1) in the first stage, at the beginning of the fatigue cycle, all mixtures should exhibit a similar trend that the strain increased gradually with a slight change in the cycle ratio. This stage accounts for about $10 \%$ of the overall fatigue life. (2) In the second stage, the strain is relatively stable, the internal microcracks slowly develop into macrocracks, and a large amount of energy is absorbed inside the mixture. The second stage accounts for most of the fatigue life of concrete. (3) In the third stage, the strain increases rapidly to the final failure point. The mixture was rapidly destroyed, accounting for $10 \%$ to $15 \%$ of the fatigue life. Under the same $S$, the SF1.0RAC is finally broken. The maximum strain before SF1.0RAC failure is $1800 \mu \varepsilon-2000 \mu \varepsilon$ under the $S$ of $0.9,0.7$, 


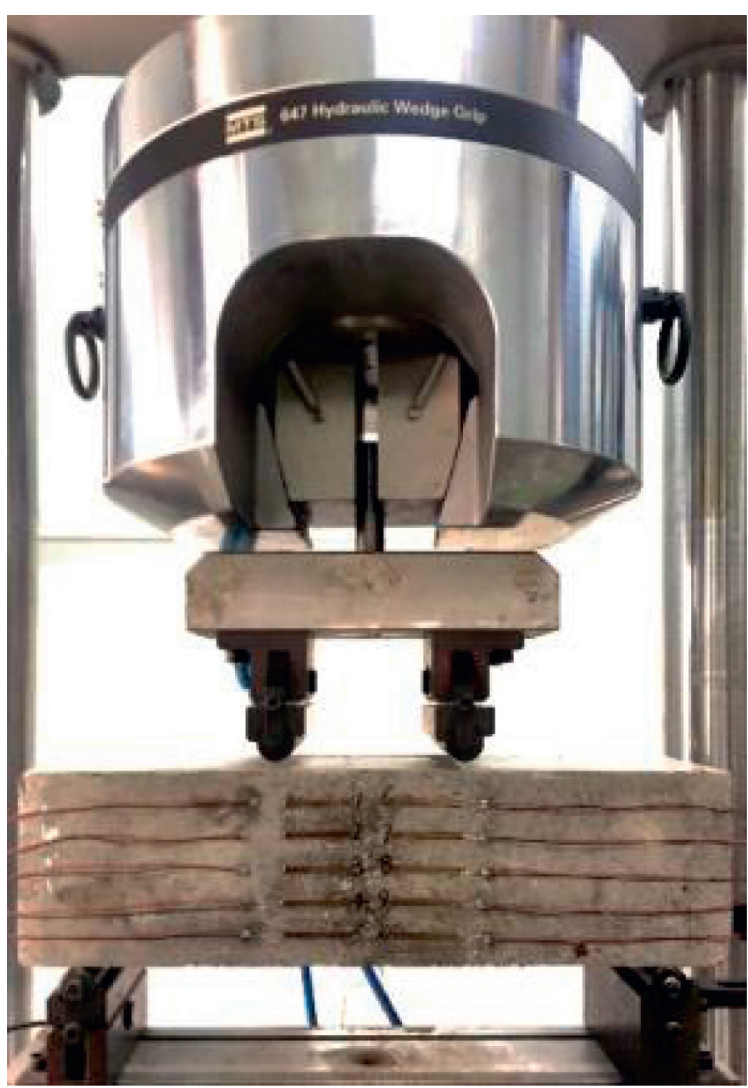

Figure 6: Flexural fatigue test.

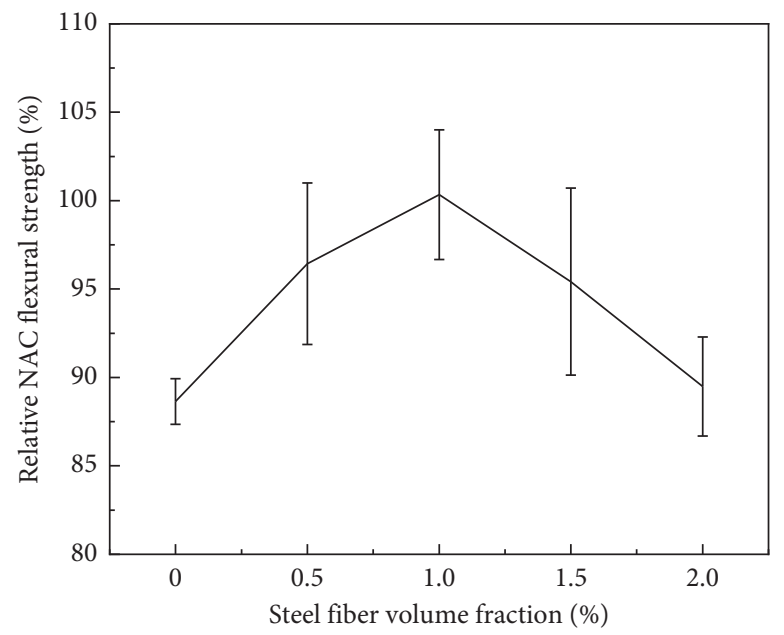

Figure 7: Reduction in flexural strength of recycled concrete compared to natural concrete.

and 0.6. Comparing SFRAC with RAC, the strain growth of SFRAC in the second stage is slower. The steel fiber improves concrete microcracks. The fatigue failure of mixtures is shown in Figure 10.

\section{Statistical Analysis}

4.1. Weibull Distribution Analysis. Normal distribution and Weibull distribution are widely accepted as probabilistic models for statistical analysis of fatigue life. This article is based on the Weibull distribution. Previous studies [26, 27] have got a conclusion that the concrete flexural fatigue life followed the Weibull distribution. In this study, the fatigue life data of the mixture conform to the Weibull distribution. Finally, the relationship between survival probability and $N$ was found. According to the Weibull distribution, under the same $S$ and the same cyclic load, the distribution of $N$ with different mixtures can be expressed by the Weibull distribution function: 
TABLE 4: Flexural fatigue testing results.

\begin{tabular}{lccccc}
\hline Mixtures & $S$ & \multicolumn{3}{c}{ Fatigue life } & Average fatigue life \\
\hline \multirow{4}{*}{ NAC } & 0.9 & 239 & 348 & 513 & 367 \\
& 0.7 & 6594 & 28156 & 41645 & 25465 \\
& 0.6 & 76164 & 94618 & 138495 & 103092 \\
\hline \multirow{3}{*}{ RAC } & 0.9 & 133 & 184 & 308 & 208 \\
& 0.7 & 3459 & 16894 & 38946 & 19766 \\
& 0.6 & 38469 & 50496 & 76184 & 55050 \\
\hline \multirow{3}{*}{ SF0.5RAC } & 0.9 & 167 & 305 & 416 & 296 \\
& 0.7 & 5184 & 28461 & 37154 & 23600 \\
& 0.6 & 46491 & 84134 & 112463 & 81029 \\
\hline \multirow{3}{*}{ SF1.0RAC } & 0.9 & 346 & 413 & 614 & 458 \\
& 0.7 & 41674 & 52196 & 70154 & 54675 \\
\hline \multirow{3}{*}{ SF1.5RAC } & 0.6 & 76194 & 94347 & 134954 & 101832 \\
& 0.9 & 238 & 346 & 564 & 383 \\
& 0.6 & 54976 & 34647 & 39176 & 33256 \\
SF2.0RAC & 0.7 & 31459 & 37158 & 45416 & 38011 \\
& 0.6 & 38461 & 50169 & 71946 & 53525 \\
\hline
\end{tabular}

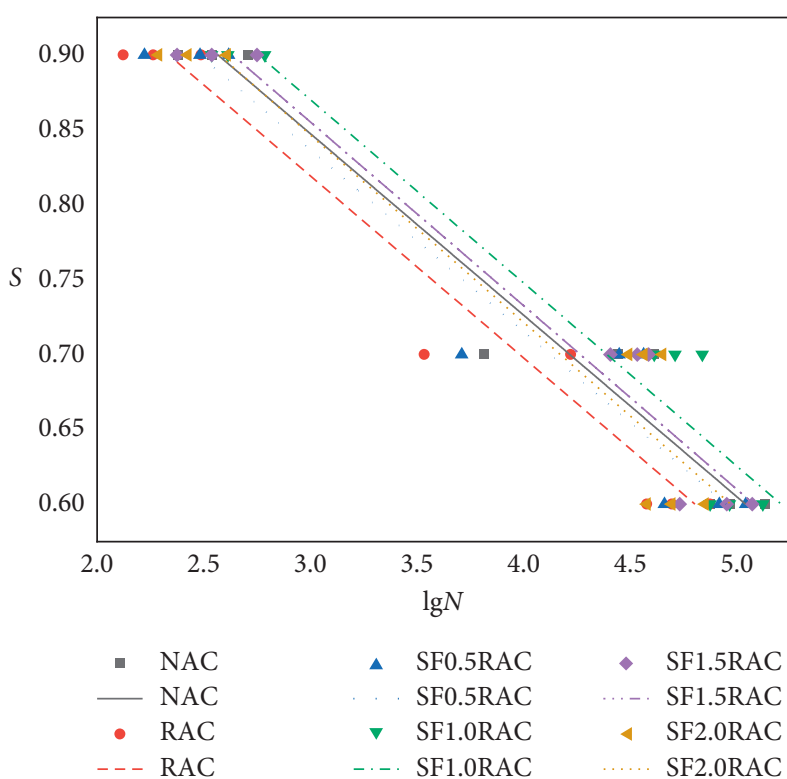

FIgURE 8: S-N curve of mixture under cyclic loading.

$$
\begin{aligned}
f(N) & =\frac{b}{N_{a}-N_{0}}\left[\frac{N-N_{0}}{N_{a}-N_{0}}\right]^{b-1} \\
& \exp \left\{-\left[\frac{N-N_{0}}{N_{a}-N_{0}}\right]^{b}\right\}, \quad\left(N_{0} \leq N<\infty\right) .
\end{aligned}
$$

In equation (1), $b$ is the Weibull distribution shape function, $N_{0}$ is the minimum life parameter, $N_{a}$ is the characteristic life parameter, and $N$ is called the Weibull variable. The empirical survival probability $(P)$ [28] is expressed as follows:

$$
P=1-\frac{i}{(K+1)}
$$

$K$ is the sample capacity at a given $S$, and $i$ is the ordinal number of fatigue life data in ascending order from low to high. As the number of tested samples increases, $N$ can be approximated as a continuous random variable, and a continuous probability density function, $P$, is used to describe the variability in the test results. Furthermore, the cumulative distribution function $P$ is given as

$$
P=P\left(N>N_{P}\right)=1-F\left(N_{P}\right)=\exp \left\{-\left[\frac{N-N_{0}}{N_{a}-N_{0}}\right]^{b}\right\} \text {, }
$$

where $P\left(N>N_{P}\right)$ represents the survival probability of mixtures after stress cycles were applied. Considering the large dispersion of SFRAC, in order to facilitate calculation and ensure reliability, let the minimum life $N_{0}$ be 0 . The Weibull probability function is reduced to a two-parameter Weibull distribution function

$$
f(N))=\frac{b}{N_{a}}\left[\frac{N}{N_{a}}\right]^{b-1} \exp \left\{-\left[\frac{N}{N_{a}}\right]^{b}\right\}, \quad(0 \leq N \leq \infty),
$$

and survival probability $P$ :

$$
P=P\left(N>N_{P}\right)=1-F\left(N_{P}\right)=\exp \left\{-\left[\frac{N_{P}}{N_{a}}\right]^{b}\right\} .
$$

By taking the logarithm twice of both sides of equation (5), the following equation can be obtained:

$$
\begin{aligned}
\ln \left[\ln \left(\frac{1}{P}\right)\right] & =b \ln N_{P}-b \ln N_{a}, \\
Y & =b X-c
\end{aligned}
$$

where $Y=\ln [\ln (1 / P)], X=\operatorname{In} N_{P}$, and $c=b \quad \ln \quad N_{a}$. To predict the fatigue life $\left(N_{P}\right)$ of each mixture, $b$ and $c$ are necessary, which are the two important input parameters for predicting the fatigue life. The parameters $b$ and $c$ of equation (7) are the regression parameters of the straight line obtained by fitting the $X$ - and $Y$-data, as shown in Figure 11 . The value of $R^{2}$ of each equation ranged from 0.8370 to 0.9877 (mostly larger than 0.9) indicating that the fatigue equations developed in this study are reliable to be used to predict the flexural fatigue performance for a concrete mixture. The value of $R^{2}$ of fitting the $X$ - and $Y$-data ranged from 0.89483 to 0.99618 indicating that the two-parameter Weibull distribution developed is reliable to be used to predict the flexural fatigue performance for mixtures, as shown in Table 5 .

4.2. Prediction of Fatigue Life. As the fatigue life data of SFRAC have been shown to follow the two-parameter Weibull distribution, it can be used to calculate the fatigue lives corresponding to different reliability levels. Due to the 


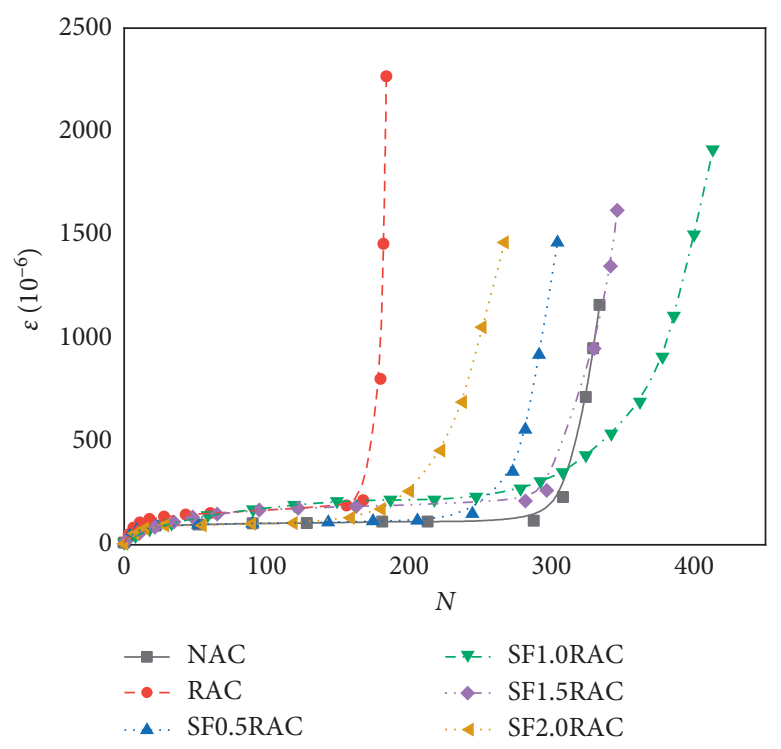

(a)

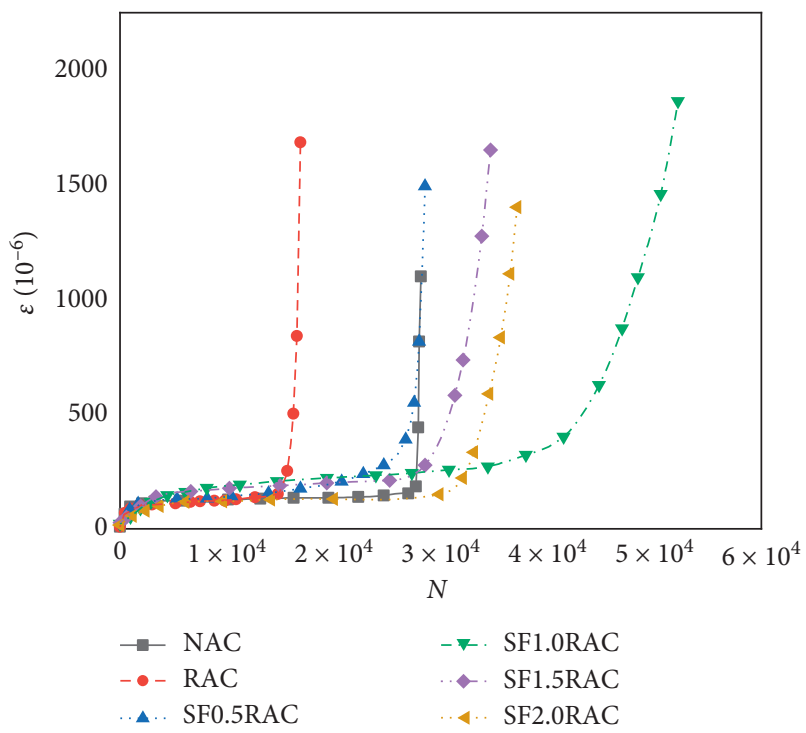

(b)

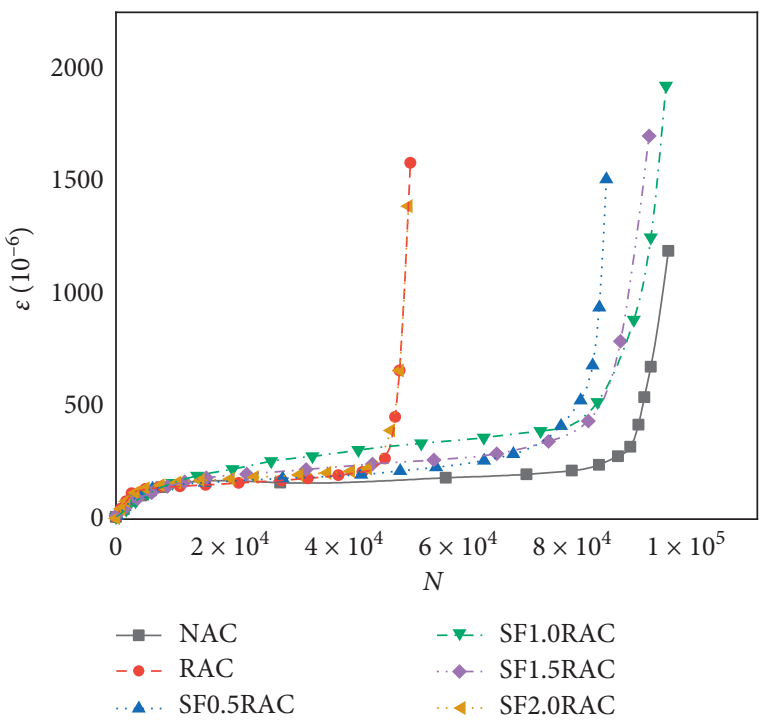

(c)

FIgURE 9: Comparison of fatigue strain variation: (a) $S=0.9$; (b) $S=0.7$; (c) $S=0.6$.

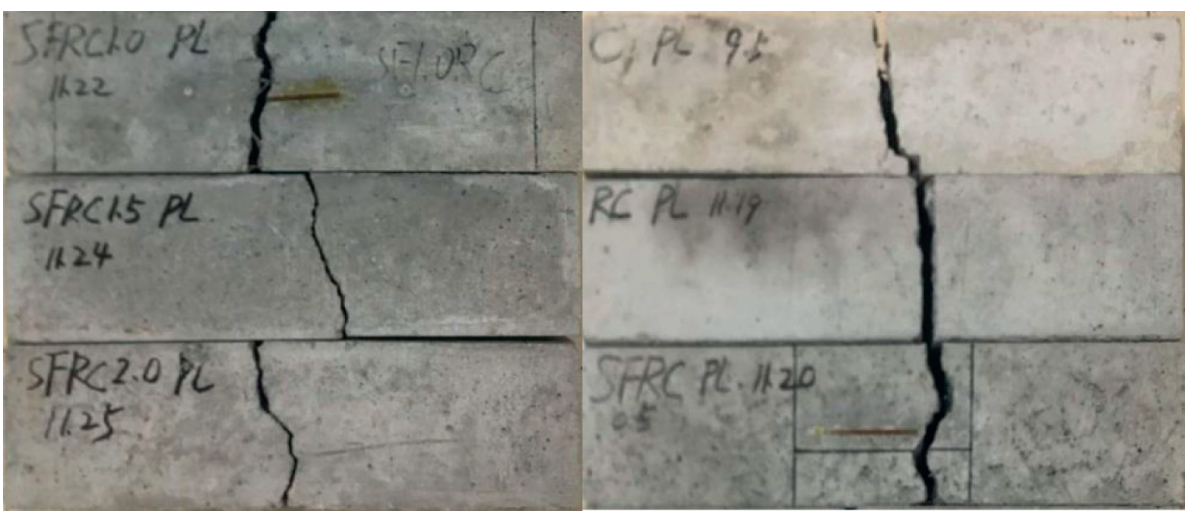

FIgURE 10: Fatigue failure. 

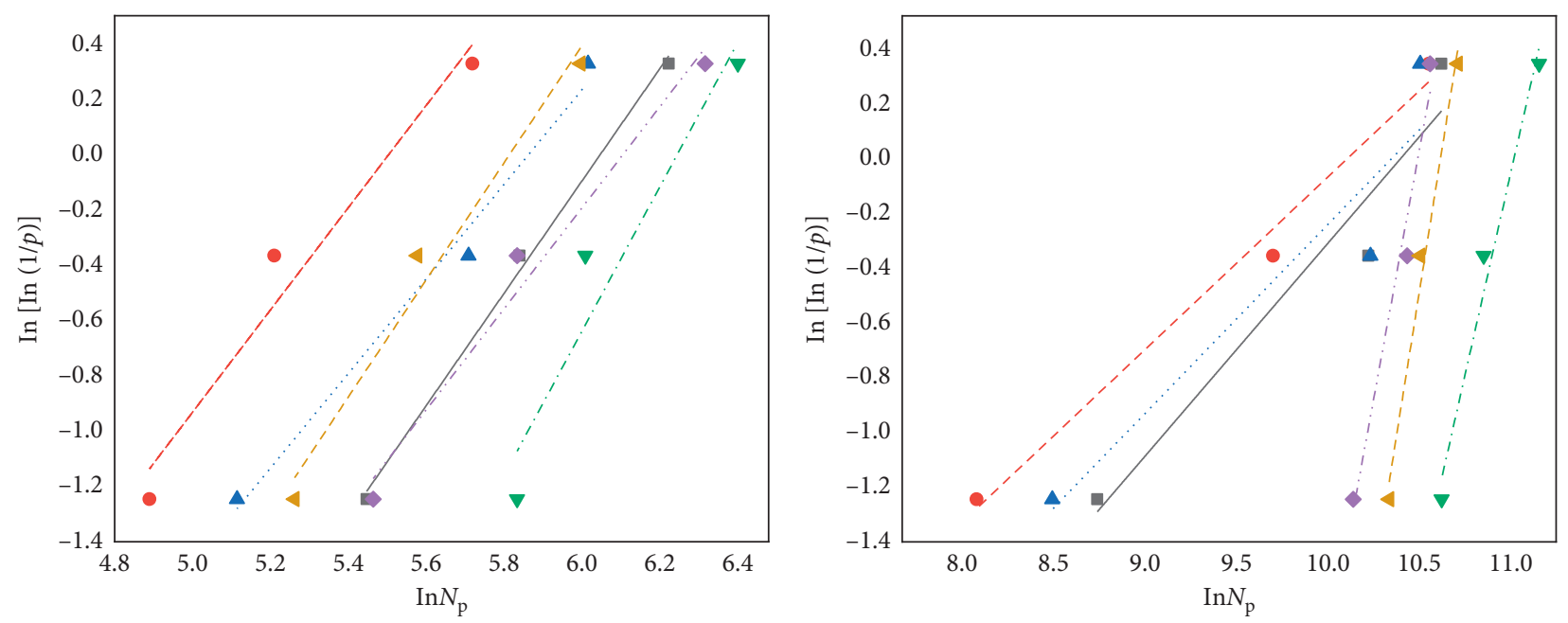

- NAC

- RAC

$\checkmark$ SF1.0RAC

- SF0.5RAC

4 SF2.0RAC

SF1.5RAC

- NAC

- - RAC

- NAC

- SF0.5RAC

- RAC

- SF1.5RAC

- NAC

$\checkmark$ SF1.0RAC

..... SF0.5RAC

- - SF1.0RAC

.... SF1.5RAC

- - SF2.0RAC

(a)

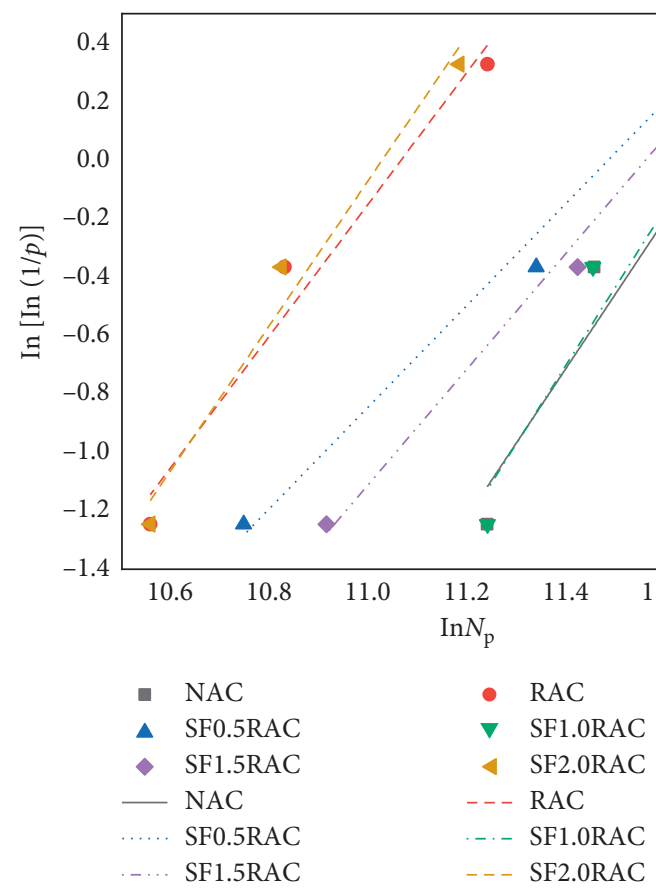

(b)

(c)

FIGURE 11: Graphical analysis of fatigue life data for all mixtures: (a) $S=0.9$; (b) $S=0.7$; (c) $S=0.6$. 
TABLE 5: Weibull distribution parameters.

\begin{tabular}{lcccc}
\hline Mixtures & $S$ & $b$ & $c$ & $R^{2}$ \\
\hline \multirow{3}{*}{ NAC } & 0.9 & 2.00399 & 12.15046 & 0.99618 \\
& 0.7 & 0.78592 & 8.20299 & 0.93765 \\
& 0.6 & 2.5375 & 29.64101 & 0.95008 \\
\hline \multirow{2}{*}{ RAC } & 0.9 & 1.82436 & 10.05838 & 0.96108 \\
& 0.7 & 0.63701 & 6.47025 & 0.9882 \\
& 0.6 & 2.25161 & 24.9172 & 0.966 \\
\hline \multirow{3}{*}{ SF0.5RAC } & 0.9 & 1.68715 & 9.91543 & 0.98699 \\
& 0.7 & 0.6977 & 7.25035 & 0.89483 \\
& 0.6 & 1.73609 & 19.94081 & 0.98391 \\
\hline \multirow{3}{*}{ SF1.0RAC } & 0.9 & 2.57424 & 16.12271 & 0.9202 \\
& 0.7 & 2.98509 & 32.92512 & 0.97878 \\
& 0.6 & 2.66652 & 31.1011 & 0.95531 \\
\hline \multirow{3}{*}{ SF1.5RAC } & 0.9 & 1.8024 & 11.03497 & 0.97917 \\
& 0.7 & 3.67766 & 38.66715 & 0.97437 \\
& 0.6 & 1.97524 & 22.83735 & 0.98922 \\
\hline \multirow{2}{*}{ SF2.0RAC } & 0.9 & 2.08966 & 12.17696 & 0.97781 \\
& 0.7 & 4.25435 & 45.24525 & 0.98519 \\
& 0.6 & 2.47691 & 27.31486 & 0.97605 \\
\hline
\end{tabular}

factors of the concrete material itself, microcracks inevitably exist inside. Under the action of cyclic load, microcracks will continue to develop and it will eventually be destroyed. Therefore, the boundary conditions of the fatigue equation of concrete materials are

$$
\left\{\begin{array}{l}
N=1, \quad S=1 \\
N \longrightarrow \infty, \quad S \longrightarrow 0
\end{array}\right.
$$

The most common is the single-logarithmic fatigue equation and the double-logarithmic fatigue equation. The single-logarithmic fatigue equation does not satisfy the boundary conditions in equation (8). Given the $P-S-N$ fatigue equation under the condition of survival probability, this meets the requirements of safety performance under cyclic loading in engineering. The form of the logarithmic fatigue equation is as follows:

$$
\lg S=\lg a-\lambda \lg N .
$$

Combining fatigue test data with two parameters of the Weibull distribution function,

$$
N=N_{a}\left(\operatorname{In} \frac{1}{P}\right)^{(1 / b)} .
$$

Moreover, equation (10) can be expressed as

$$
N=e^{(c / b)}\left(\operatorname{In} \frac{1}{P}\right)^{(1 / b)}
$$

The fatigue life under different survival conditions can be obtained through the calculation, as shown in Figure 12. Double-fatigue equation parameters, $\lg a$ and $\lambda$, can be obtained by linear fitting, thereby obtaining double-logarithmic fatigue equations for concrete samples of different proportions under different survival probabilities. When the reliability levels are 0.50 and 0.90 , the logarithmic fatigue equation of each mixture is shown in Figure 12.

Fatigue equations of all mixtures are developed under different reliability levels. When the survival probability $P$ is 0.90 , the fatigue equation is

$$
\begin{aligned}
& \text { NAC: } \lg S=0.09029-0.06849 \lg N, \\
& \text { RAC: } \lg S=0.06604-0.06815 \lg N, \text { SF0.5RAC: } \lg S=0.08514-0.07128 \lg N, \\
& \text { SF1.0RAC: } \lg S=0.11019-0.06547 \lg N, \\
& \text { SF1.5RAC: } \lg S=0.09191-0.06380 \lg N, \\
& \text { SF2.0RAC: } \lg S=0.08094-0.06133 \lg N .
\end{aligned}
$$

When the survival probability $P$ is 0.50 , the fatigue equation is

$$
\begin{aligned}
& \text { NAC: } \lg S=0.13518-0.06962 \lg N, \\
& \text { RAC: } \lg S=0.11751-0.06917 \lg N, \\
& \text { SF0.5RAC: } \lg S=0.12818-0.06934 \lg N, \\
& \text { SF1.0RAC: } \lg S=0.13386-0.06646 \lg N, \\
& \text { SF1.5RAC: } \lg S=0.13418-0.06856 \lg N, \\
& \text { SF2.0RAC: } \lg S=0.11848-0.06615 \lg N .
\end{aligned}
$$

It can be seen that the overall relationship between the established double-logarithmic fatigue equation and experimental data is good. Therefore, the double-logarithmic fatigue equation established in this paper can meet the requirements of practical engineering applications. After adding recycled aggregates to natural concrete, the fatigue strength of concrete has been reduced slightly, but the fatigue strength has been increased to a certain extent after the steel fiber is added to the recycled concrete, and it increases first and then decreases, similar to the four-point bending test results. This shows that the incorporation of steel fiber can effectively improve the fatigue strength of recycled concrete and make up for the decrease in fatigue performance caused by the addition of recycled aggregate.

4.3. Pervious Concrete Fatigue Models Comparison. The single-log fatigue equation of SF1.0RAC in the present study and the steel fiber-reinforced concrete (SFRC) in previous studies [28] at survival probability of $90 \%$ are shown in Figure 13. The single-log fatigue equation has been used to calculate the fatigue lives at different stress levels corresponding to a survival probability of $90 \%$. It can be seen from Figure 13 that, for $S$ values above 0.80, SF1.0RAC fatigue showed higher values for $\lg N$ than the corresponding values for $\lg N$ for SFRC. Furthermore, at $S$ values lower than 0.75 , the SF1.0RAC shows lower fatigue life predictions than SFRC. For $S$ values lower than 0.5 , which are common for pavement applications, SF1.0RAC showed a lower fatigue life compared to SFRC. 

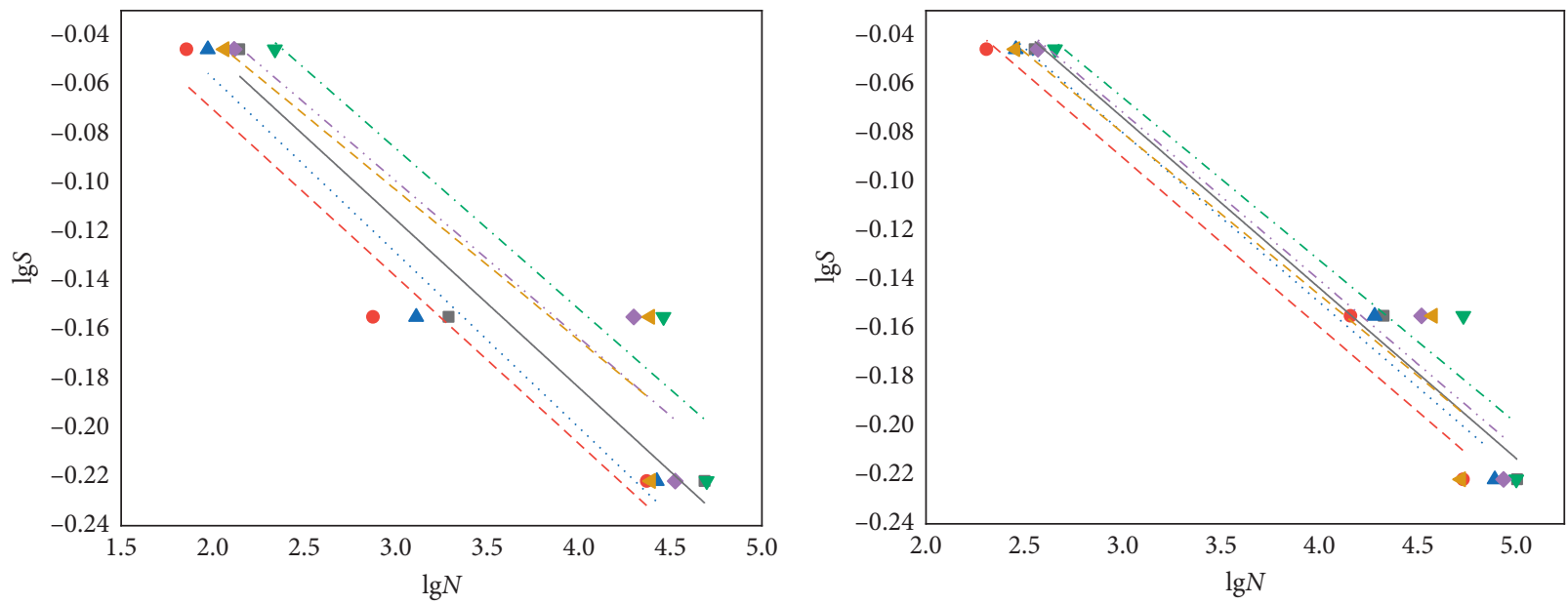

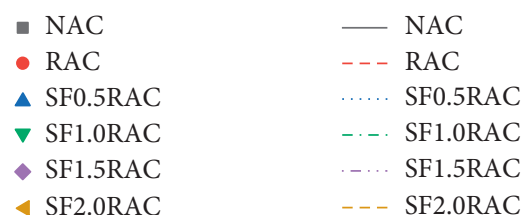

(a)

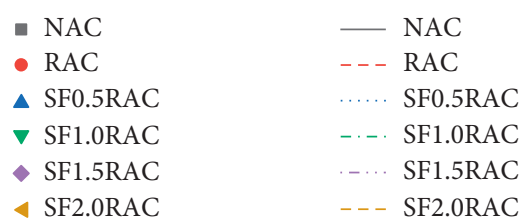

(b)

FIgURE 12: Log SR versus $\log \mathrm{N}$ curves for (a) $90 \%$ survival probability and (b) $50 \%$ survival probability.

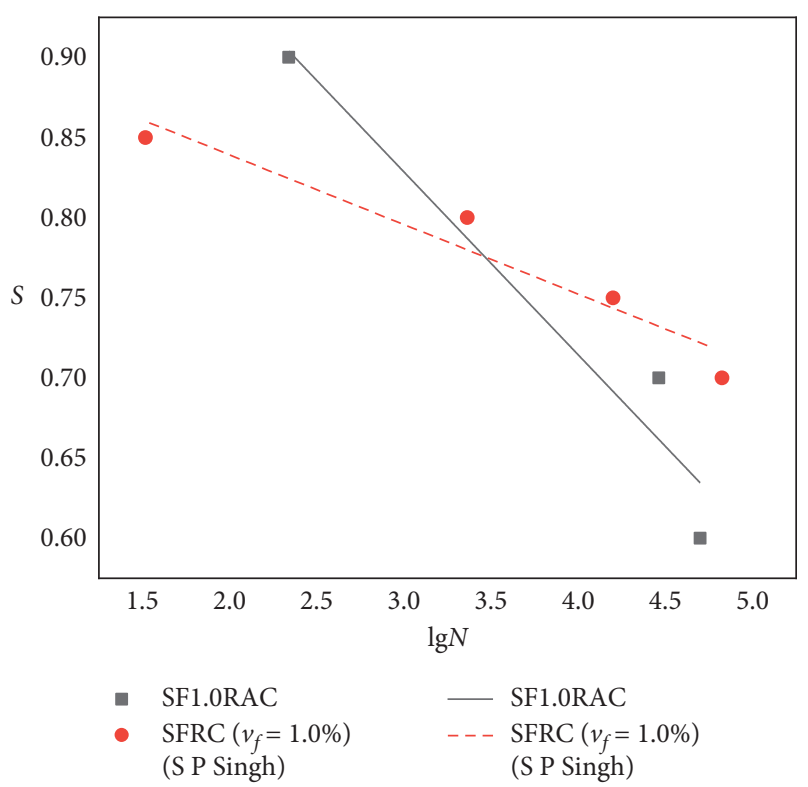

FIGURE 13: Single-log fatigue of SF1.0RAC in the present and steel fiber-reinforced concrete in the present and previous studies.

\section{Conclusion}

(1) When the $S$ is constant, the fatigue life of RAC is lower than NAC; however, with the addition of steel fiber, the SFRAC is increased than RAC. When the steel fiber content is $1.0 \%$, the fatigue life of SF1.0RAC is the longest, and the strength is increased the most. It is not only equivalent to the fatigue strength of NAC but also $8.1 \%$ higher than the RAC fatigue strength.

(2) The fatigue strain of SFRAC follows the three-stage law. The strain growth of steel fiber recycled aggregate concrete in the second stage is slower. The steel fiber improves concrete microcracks.

(3) The fatigue life of NAC, RAC, and SFRAC can well obey the two-parameter Weibull distribution, and the fitted fatigue life equation has a good correlation. The fatigue test data have been used to develop S-N-P curves for SFRAC, and a relationship between stress level, fatigue life, and survival probability has been established. The $S-N-P$ model of SFRAC can be used for future roads, bridges, and railways design.

(4) At lower $S$ values, SFRAC fatigue life is not as good as steel fiber-reinforced concrete. SFRAC cannot completely replace steel fiber-reinforced concrete for pavement.

\section{Data Availability}

All data used to support the findings of this study are available from the corresponding author upon request.

\section{Conflicts of Interest}

The authors declare that they have no conflicts of interest.

\section{Acknowledgments}

This research was funded by the Major Technological Innovation Program of Hubei Province (Grant no. 
2018AAA028) and the State Key Laboratory for Health and Safety of Bridge Structures (Grant no. BHSKL19-04-KF). The authors would like to express their appreciation to these financial assistances.

\section{References}

[1] S. Yuedong and X. Jianzhuang, "Aggregate of recycled concrete," Concrete, vol. 6, pp. 33-36, 2004.

[2] A. Yazdanbakhsh, L. C. Bank, T. Baez, and I. Wernick, "Comparative LCA of concrete with natural and recycled coarse aggregate in the New York City area," The International Journal of Life Cycle Assessment, vol. 23, no. 6, pp. 1163-1173, 2018.

[3] S. Yuting, "Experimental study on flexural capacity of SFRC beam with different rate of steel fiber," Xihua University, Chengdu, China, Master Degree, 2013.

[4] S. Arora and S. P. Singh, "Fatigue strength and failure probability of concrete made with RCA," Magazine of Concrete Research, vol. 69, no. 2, pp. 55-67, 2017.

[5] J. Xiao, D. D. Xin, L. X. Wen, and X. Gen, "Quantitative analysis of damage evolution as recycled concrete approaches fatigue failure," Journal of Central South University (Science and Technology), vol. 42, no. 1, pp. 170-176, 2011.

[6] C. Thomas, J. Setién, J. A. Polanco, I. Lombillo, and A. Cimentada, "Fatigue limit of recycled aggregate concrete," Construction and Building Materials, vol. 52, pp. 146-154, 2014.

[7] J. Xiao, H. Li, and Z. Yang, "Fatigue behavior of recycled aggregate concrete under compression and bending cyclic loadings," Construction and Building Materials, vol. 38, pp. 681-688, 2013.

[8] F. Liu, L.-Y. Meng, G.-F. Ning, and L.-J. Li, "Fatigue performance of rubber-modified recycled aggregate concrete (RRAC) for pavement," Construction and Building Materials, vol. 95, pp. 207-217, 2015.

[9] A. R. Pasandín and I. Pérez, "Fatigue performance of bituminous mixtures made with recycled concrete aggregates and waste tire rubber," Construction and Building Materials, vol. 157, pp. 26-33, 2017.

[10] M. Arabani, F. M. Nejad, and A. R. Azarhoosh, "Laboratory evaluation of recycled waste concrete into asphalt mixtures," International Journal of Pavement Engineering, vol. 14, no. 6, pp. 531-539, 2013.

[11] F. M. Nejad, A. R. Azarhoosh, and G. H. Hamedi, "The effects of using recycled concrete on fatigue behavior of hot mix asphalt," Journal of Civil Engineering and Management, vol. 19, no. Supplement_1, pp. S61-S68, 2013.

[12] Y. Q. Hou, X. P. Ji, J. Li, and X. H. Li, “Adhesion between asphalt and recycled concrete aggregate and its impact on the properties of asphalt mixture," Materials, vol. 11, no. 12, p. 15, 2018.

[13] A. Albayati, Y. Wang, Y. Wang, and J. Haynes, "A sustainable pavement concrete using warm mix asphalt and hydrated lime treated recycled concrete aggregates," Sustainable Materials and Technologies, vol. 18, no. 12, 2018.

[14] S. Wu, B. Muhunthan, and $\mathrm{H}$. Wen, "Investigation of effectiveness of prediction of fatigue life for hot mix asphalt blended with recycled concrete aggregate using monotonic fracture testing," Construction and Building Materials, vol. 131, pp. 50-56, 2017.

[15] R. N. Yang and D. M. Wei, "A study on the residual fatigue strain and damage of steel fiber reinforced recycled concrete under constant amplitude flexural fatigue loading," Journal of
Testing and Evaluation, vol. 41, no. 3, pp. 465-470, Article ID 20120135, 2013.

[16] Z. Fang, Y. Xiang, Z. Kuang, and C. Wang, "Fatigue properties of reactive powder concrete with different steel fiber ratios," Journal of Hunan University (Natural Science), vol. 38, no. 6, pp. 6-12, 2011.

[17] Y. Mei, X. Zhao, C. Dai, and C. Xiang, "Fatigue life of steel fiber reinforced polymer concrete under bending load," Journal of Highway and Transportation Research and Development, vol. 32, no. 9, pp. 20-25, 2015.

[18] Z. Feng, L. Huang, M. Guo, and X. Niu, "Experimental study on fatigue of concrete with different steel fiber incorporation rates," Journal of China \& Foreign Highway, vol. 38, no. 2, pp. 269-272, 2018.

[19] S. Goel and S. P. Singh, "Fatigue performance of plain and steel fibre reinforced self compacting concrete using S-N relationship," Engineering Structures, vol. 74, pp. 65-73, 2014.

[20] Y. Hao, X. Huang, and H. Hao, "Mesoscale modelling of concrete reinforced with spiral steel fibres under dynamic splitting tension," Advances in Structural Engineering, vol. 21, no. 8, pp. 1197-1210, 2018.

[21] K. Ostrowski, L. Sadowski, D. Stefaniuk et al., "The effect of the morphology of coarse aggregate on the properties of selfcompacting high-performance fibre-reinforced concrete," Materials, vol. 11, no. 8, p. 16, 2018.

[22] B. R. Rajeshwari and M. V. N. Sivakumar, "Influence of coarse aggregate properties on specific fracture energy of steel fiber reinforced self compacting concrete," Advances in Concrete Construction, vol. 9, no. 2, pp. 173-181, 2020

[23] National Standardizing Committee of the People's Republic of China, "General administration of quality supervision inspection and quarantine of the People's Republic of China," Common Portland Cement, National Standardizing Committee of the People's Republic of China, Beijing, China, 2007.

[24] Ministry of Housing and Urban Rural Development of the People's Republic of China, Specification for Mix Proportion Design of Ordinary Concrete, Ministry of Housing and Urban Rural Development of the People's Republic of China, China, 2011.

[25] Ministry of Housing and Urban Rural Development of the People's Republic of China, Standard for Test Method of Mechanical Properties on Ordinary Concrete, Ministry of Housing and Urban Rural Development of the People's Republic of China, China, 2002.

[26] B. Oh, "Fatigue analysis of plain concrete in flexure," Journal of Structural Engineering-ASCE, vol. 112, 1986.

[27] B. Oh, "Fatigue-life distributions of concrete for various stress levels," ACI Materials Journal, vol. 88, pp. 122-128, 1991.

[28] S. P. Singh and S. K. Kaushik, "Flexural fatigue life distributions and failure probability of steel fibrous concrete," ACI Materials Journal, vol. 97, no. 6, pp. 658-667, 2000. 